\title{
Golfing Alone? Corporations, Elites, and Nonprofit Growth in 100 American Communities
}

\author{
Christopher Marquis \\ Harvard Business School, Harvard University, Boston, Massachusetts 02163, \\ cmarquis@hbs.edu \\ Gerald F. Davis \\ Stephen M. Ross School of Business, University of Michigan, Ann Arbor, Michigan 48109, \\ gfdavis@umich.edu \\ Mary Ann Glynn \\ Carroll School of Management, Boston College, Chestnut Hill, Massachusetts 02467, \\ maryann.glynn.1@bc.edu
}

\begin{abstract}
$\mathrm{W}^{\mathrm{c}}$ e examine the link between corporations and community by showing how corporate density interacts with the local social and cultural infrastructure to affect the growth and decline of the number of local nonprofits between 1987 and 2002. We focus on two subpopulations of nonprofits in 100 American cities: (1) elite-oriented cultural and educational institutions and (2) social welfare-oriented organizations. We find that corporate density enhances the growth of both types of nonprofits, as does location in the northeast United States and a long-established business community, but corporate density is especially potent for the growth of elite-oriented nonprofits-but not social welfare nonprofitswhen local networks and cultural norms support elite mobilization. We conclude that despite globalizing trends, the local geographic community continues to be an important unit of analysis for unpacking multisector organizational processes among corporations and nonprofits.
\end{abstract}

Key words: institutional theory; social responsibility; interorganizational relations; nonprofit organizations History: Published online in Articles in Advance December 22, 2011.

\section{Introduction}

The benefit of the corporation to society has been debated extensively over the past century (Margolis and Walsh 2003, Avi-Yonah 2005). Some view the corporation as an intrinsically social institution with the potential for broad public benefit (e.g., Dodd 1932, Kaysen 1957, Elkington 1998), whereas others see the corporation as a device prone to promoting self-serving behavior and narrow interests (e.g., Berle 1931, Jensen 2002). Over the past 30 years, this debate has focused on the perspective of the corporation and, in particular, on the extent to which corporate social action profits the corporation itself, rather than its supposed societal beneficiaries (Margolis and Walsh 2003). This narrowing of focus can be seen as part of a broader trend in organizational theory. Whereas the effect of corporations on society was a central concern for early organizational theorists (e.g., Michels 1962, Weber 1964), it has largely been ignored as of late (Hinings and Greenwood 2002, Stern and Barley 1996). Seeking to reverse this trend, we address the issue of who benefits from the existence of corporations. We do so by examining how corporations influence the vibrancy of their local nonprofit sector, differentiating the effects on those nonprofits that address broader social welfare interests from those that disproportionally benefit the elite.

Our approach to this issue focuses on two interrelated questions: How does the community-level institutional infrastructure exert pressures on organizations that affect the vitality of local nonprofit sectors? And, more specifically, how do elite interests and the social organization of the local elite influence the link between the corporate and nonprofit sectors? We focus on local nonprofit sectors because they are vital to the civic health of communities and provide social services, education, medical care, and cultural enrichment that are beyond the reach of the market (Powell and Steinberg 2006). Local nonprofits are thus a site where the interests and needs of a community intersect in "a particular combination of ideological, political, social, and economic conditions" (Hall 1987, p. 3). Our general aim is to unpack variation at the community level to better understand the interplay between corporate engagement and local nonprofits, addressing the question of why nonprofits in some communities thrive, as in the Twin Cities (Galaskiewicz 1985, 1991, 1997), while those in other communities, equally endowed with major corporations, do not (e.g., Detroit). 
We examine how the social and cultural infrastructure of local corporate sectors shape the growth and decline of nonprofits in 100 American communities. Examining variation across local organizational populations across a large number of communities over time enables us to identify those institutional features of a community that make it more or less fertile for the maintenance and growth of nonprofits (Marquis et al. 2007). Building on Warren's (1967) foundational research on interorganizational communities as well as work on community elites (e.g., Hunter 1953, Kono et al. 1998) and the community ecology of organizations (e.g., Freeman and Audia 2006), we conceptualize the geographic community as an institutional field - that is, a more or less integrated set of corporate, nonprofit, and governmental actors that "partake of a common meaning system and...interact more frequently and fatefully with one another than with actors outside the field" (Scott 2001, p. 84). In so doing, we overcome a weakness of prior work on institutional fields in focusing on specific industries with limited generalizability (Davis 2010) and return attention to the comparative institutional perspective envisioned in early work on neo-institutional theory (DiMaggio and Powell 1983). Although the preponderance of recent research has focused on geographically independent fields (Scott 2001), there is increasing recognition that such a perspective misses important reasons why corporations and nonprofits maintain their local focus even in a global age (Marquis and Battilana 2009, Marquis et al. 2011). We seek to address this oversight.

Prior research on the growth and decline of local nonprofit sectors has emphasized the role of factors such as needs of residents (Weisbrod 1998), governmental outsourcing (Salamon 1987), and the demographic and social changes that induce individuals toward "bowling alone" rather than engaging in nonprofit voluntarism (Putnam 2000). However, there is also evidence that the decisions of those controlling the means and ends of large organizations - the corporate elite-weigh heavily in shaping the nonprofit sector of local communities (see, e.g., Galaskiewicz 1997 on Minneapolis-St. Paul). Local nonprofit sectors are diverse, serving a range of community interests from social welfare needs such as homelessness, civil rights, mental illness, unemployment, illiteracy, and food security to providing "luxury goods" (Heilbrun and Gray 2001, p. 16) in the arts, culture, and private education. By treating the nonprofit sector as a relatively undifferentiated field, much prior work overlooks how different kinds of dynamics may animate the relations between businesses and social welfare organizations, on the one hand, and businesses and elite high-status cultural and educational institutions, on the other.

We reason that such systematic differences may be related to elite interests in, and support of, different types of nonprofit organizations. Odendahl (1990), for instance, demonstrated that the charitable wealthy fund nonprofits in ways that promote the needs of their class: "The wealthy fund institutions of higher learning, art, or music primarily, rather than basic human services not provided by the state, such as for the homeless" (Nader 1991, p. 483). The class Mills (1956) labeled the "corporate rich" has long since replaced the "old money rich" as the most critical source of support for high-status cultural and educational institutions, and longstanding sociological research has shown that these high-status organizations function in part to promote local elite cohesion (DiMaggio 1986, Useem 1988). Extending this line of reasoning, we hypothesize that the growth of local elite-oriented nonprofits will be greater when corporations are in communities characterized by dense social and cultural infrastructures that promote elite cohesion and interests. That is, in some communities, the elite will be effectively "golfing alone," without a supportive social and cultural infrastructure to organize efforts, while in others these external environmental factors will enable more coordinated corporate action.

To test these ideas, we assembled community-level data from the census for every major American urban area $;{ }^{1}$ Internal Revenue Service (IRS) records on several thousand nonprofits; and securities filings for every corporation listed on NASDAQ and the New York Stock Exchange to examine changes at the community level in 1987, 1992, 1997, and 2002. ${ }^{2}$ Our time period is theoretically significant, as the governmental stance toward nonprofits changed as a result of the 1986 Reagan tax reforms, which led to a period of unusual growth in this sector (Abzug and Simonoff 2004, Salamon 1987). Such a period of change is ideal for investigating our research questions. In addition, many of the corporate, social, and cultural factors we study varied substantially within and across American cities in this same period. The 1980s and 1990s witnessed the two largest merger waves in U.S. history: nearly one in three Fortune 500 manufacturers were acquired in the 1980s, as conglomerates were divided and sold or spun off (Davis et al. 1994). Subsequently, an even larger merger wave and a spate of corporate relocations in the 1990s rearranged the geography of corporate headquarters.

Foreshadowing our results, we find support for our core premise: although a dense corporate sector was associated with growth across all types of nonprofits, having a locally cohesive elite and a supportive local culture was particularly effective at spurring the growth of elite-oriented nonprofits. Thus, our work reinforces the integrity of the local community as a field of study for organizational behavior and contributes to understanding the institutional processes underlying the growth of nonprofits in the United States.

\section{Nonprofit Sectors in U.S. Communities}

The nonprofit sector sits at the intersection between the state and the market (Frumkin 2002) and is large 
and complex, consisting of nearly one million nonprofit organizations, ranging from art museums and universities to soup kitchens and women's shelters. What unites these diverse organizations is their tax-exempt status under section 501(c)(3) of the IRS code. Their funding is based primarily on donative or membership sources, which can come from corporations, individuals, government, or other nonprofits. As of 2002 (the end of our time period), roughly 200,000 nonprofit organizations employed 8.8 million persons, or $8.2 \%$ of the private labor force, which is "nearly three times as many workers as the country's entire agriculture sector, twice as many workers as the country's transportation industry, 60 percent more workers than the Nation's wholesale trade industry and its finance and insurance industry, and nearly as many workers as are those employed in durable goods manufacturing" (Salamon and Sokolowski 2005 , p. 21). In some parts of the country, nonprofits are among the dominant sectors of the economy. In New England, for instance, $13 \%$ of all private employment is in nonprofit organizations.

In most cases, nonprofit activity is centered at the community level, both in terms of the resources available and the services provided. Smith and Lipsky (1993, p. 22) describe nonprofits as "manifestations of community" because they reflect local needs and function as a central point for assembling diverse community actors. Studies show that even in a global economy, local charities continue to be an essential focus for corporate philanthropy. Guthrie's (2003) national survey of 2,776 firms' giving in 2001-2002 found that upwards of 80\% was focused on nonprofits located in the community of the company's headquarters, a figure comparable to that found earlier by Galaskiewicz (1997) and McElroy and Siegfried (1986). Corporations fund nonprofits directly through grants, sponsorships, or in-kind donations of goods or services and indirectly by providing organizing structures for nonprofit fund-raising, volunteer labor, special events (e.g., holiday parties for nonprofit clients), or as a pool for potential board members. Corporate executives are more likely to be approached by local (rather than nonlocal) nonprofits, often because they tend to travel in the same social circles as nonprofit executives and status benefits are decidedly local. Furthermore, following the Tax Reform Act of 1986 and the outsourcing of some of the traditional functions of the welfare state, nonprofit reliance on local governmental funding increased (Salamon 1987). Thus, even under globalizing forces, there are significant pressures that lead corporations and nonprofits to maintain their local focus.

Interestingly, this prior work suggests a paradoxthat the prevalence of nonprofit organizations is largely decoupled from any assessment of community needs. The Twin Cities of Minneapolis-St. Paul have more performing arts organizations than Detroit not because of the greater need for culture in Minnesota than in
Michigan but because of the well-organized corporate infrastructure supporting the arts in the Twin Cities (Galaskiewicz 1985, Marquis et al. 2007). There is an analogy here with other sociological literature: social movement organizations arise not because of the quantity of grievances in a society but because of the organizing capacity of activists (McCarthy and Zald 1977), and nation states adopt global practices as a result of legitimacy pressures and social structure as opposed to features of the countries (Meyer et al. 1997).

Put another way, the level of underlying "demand" for nonprofits is only weakly correlated with the existence of organizations to meet that demand. It is not necessarily the poorest communities that have the most social welfare organizations but often the richest, because they are the ones with the resources and organizing capacity to create such organizations. New York City hosts one of the world's greatest art museums, the Metropolitan; yet within walking distance of the Met are over a dozen other museums featuring modern and contemporary art, folk art, African American art, Hispanic art, Catholic art, Chinese art, Biblical art, art and design, and other specialties. New York has a very large installed base of art museums and other nonprofits, yet new ones are created at a rate beyond what would be warranted from its growth in population. Thus, given that community needs do not seem to fully account for the numbers or types of nonprofits in a community, we sought to discern the underlying community mechanisms that might. Understanding the differences in types of nonprofits offers a useful starting point.

\section{Types of Nonprofits: Elite-Oriented and Social Welfare-Oriented}

Tax-exempt status blankets an incredible array of nonprofit types, including religious organizations, research institutions, art museums, advocacy organizations, mental health-care providers, golf courses, and pantries providing food for low-income families. Treating all nonprofits alike (or as a single homogeneous set) would be akin to overlooking differences between auto manufacturers, banks, and hospitals. Thus, we sought to construct a mid-range typology of nonprofit organizations that focuses on distinguishing (1) those arts, culture, and educational nonprofits traditionally associated with elite interests (e.g., DiMaggio and Anheier 1990, Odendahl 1990) from (2) those focused on issues of social welfare in the community (e.g., Bielefeld and Corbin 1996, Corbin 1999). Although we recognize a residual third category that includes a diverse set of nonprofits concerned with business trade and membership associations, basic research, or the physical environment, it is not as directly focused on the focal community as the other two categories, and consequently, it is excluded from our analysis. 
The key characteristic differentiating our two focal types of nonprofits is the direct beneficiary of their services and activities. We build on the well-established nonprofit literature in sociology that suggests that the status structure of elites plays a distinct role in arts, culture, and education nonprofits. DiMaggio and Anheier (1990, p. 141) described how the advent of nonprofit organizations in the late 19th century was driven by "emerging upper classes eager to control unruly urban environments and define social boundaries" and how participation in the governance of elite nonprofits through much of the 20th century served to "promote and maintain upper-class solidarity and permit elites to monitor and control [nonprofit] policies.” Abzug (2007, p. 45, citing Odendahl 1990) noted that "elite nonprofit institutions... [include] the alma maters, museums, ... and other playgrounds of the rich and famous."

Drawing from this research, we define elite-oriented nonprofits as those organizations that focus on the enrichment of the local cultural environment or the preservation of elite-oriented values and traditions. Notably, these are nonprofits that enrich the culture, higher learning, or prestige of communities and whose primary, direct beneficiaries are white-collar, collegeeducated community residents. By contrast, we define social welfare nonprofits as those organizations that address the amelioration of local social problems or human needs in the community, such as health care, crime, housing, and other important local social concerns associated with community well-being. Whereas eliteoriented nonprofits focus on the enrichment of local culture or the preservation of elite interests, social welfare nonprofits "are intended to improve the basic social welfare status of individual lives such that society as a whole is reformed... [and are a] manifestation of values such as altruism and generosity" (Corbin 1999, p. 297). ${ }^{3}$ Focusing on these two types of nonprofits-elite-oriented and social welfare-oriented-we theorize how their growth may be linked to the local presence of corporations and the institutional infrastructure of the communities in which they operate.

\section{Nonprofit Growth and the Institutional Infrastructure of Communities}

Although early researchers (e.g., Warren 1967, Litwak and Hylton 1962) recognized the importance of geography for organizational behavior, such a view faded until recently, when researchers came to see geographic location as significant in shaping market and organizational relationships (see Freeman and Audia 2006, Marquis and Battilana 2009 for reviews). Units of analysis such as the population or field dominated, as scholars built on DiMaggio and Powell (1983) to progressively broaden the definition of field to emphasize geographically independent markets or industries. Scott (2001) speculated that organization theory abandoned community-oriented studies largely as a result of communication and technological advances that made geographic connections appear less relevant.

Yet even as globalization processes have come to govern practitioner and academic discourse, the effects of local environments endure (Marquis and Battilana 2009). For example, in their study of bank foundings, Marquis and Lounsbury et al. (2007) found that community actors were motivated to maintain localness as a reaction against more global pressures. Sorge (2005) proposed that globalizing processes have led local areas to more clearly delineate their identity. Supporting this, a number of studies have demonstrated that the prevalence of corporate practices can vary by city, ranging from takenfor-granted traditions in corporate governance and strategy (Marquis 2003, Lounsbury 2007) to controversial strategies such as golden parachutes (Davis and Greve 1997). Thus, even in an age of globalization, organizations remain tied to local communities.

Like the institutional field, the community bridges "organizational and societal levels in the study of social and community change" (DiMaggio 1986, p. 337). Perhaps the most systematic conceptualization of the importance of communities was articulated by Warren 40 years ago (1967). His study of three cities (Philadelphia, Detroit, and Boston) revealed "the American metropolitan community as a special instance for interorganizational field analysis" (p. 397) and that interaction among diverse organizational types was fundamental to the structuration of the community as a field. However, most recent work on communities as units of analysis has focused either on particular features conducive to particular industries, such as the existence of a proximate base of suppliers for the instruments industry (Audia et al. 2006) or of universities for biotechnology (Powell et al. 2005), or on a limited number of communities (Galaskiewicz 1997, Lounsbury 2007).

Conceiving of the community as an organizational field, where multisector relationships are worked out among corporations, nonprofits, governmental, and other organizations, overcomes a notable limitation of research on institutional fields. Most work that purports to take the field as the relevant unit of analysis examines a single broad industry, such as health care or higher education, as it evolves over time. Yet some of the central hypotheses entail a comparative approach that examines multiple institutional fields simultaneously. Consider Hypothesis B6 from DiMaggio and Powell (1983, p. 156): "The greater the extent of structuration of a field, the greater the degree of isomorphics." This implies that more densely connected fields will be more homogeneous than less densely connected fields, a notion only testable with data across multiple fields that vary in the density of their networks. 
Our account of the link between corporations and nonprofits focuses on the importance of organizing capacity in the community. We hypothesize that the number of nonprofits in communities will grow to the extent that (a) local corporate presence and resources are munificent, (b) corporate leaders and elites are socially cohesive, and (c) local cultural history and traditions promote a vibrant nonprofit sector. Moreover, (d) we argue that the effects of corporate density on eliteoriented nonprofits will be magnified to the extent that elites are socially cohesive and embedded in supportive cultural environments.

\section{Corporate Density in Communities}

Locally based corporations are essential constituents of communities. They are visible symbols of a city's economy and provide employment and leadership in the community. We consider two mechanisms by which a large population of corporations in the community could lead to growth in the local population of nonprofits: directly, through their resource funding and support, and indirectly, through their ambient presence. Our primary interest, the direct mechanism of support, includes the resources corporations provide in the form of financial donations and personnel support. For instance, corporate executives are more likely to be approached for donations by local nonprofits (than nonlocal ones) because they tend to travel in the same social circles; status benefits from such associations are decidedly local. Moreover, because they are local, corporate investments in the community are easier to monitor and influence. Recent and extensive corporate relocations have revealed this connection. For instance, Chicago's nonprofit sector benefited from Boeing's 2002 headquarters relocation there. Conversely, in Pittsburgh, "[c]ivic organizations that lost money and volunteer support on account of Gulf's sale include hospitals, colleges, museums and the world renowned Pittsburgh Symphony" (Hirsch 1987, p. 68). In addition, even if corporations do not give directly, their mere presence helps to mobilize the citizenry to the benefit of their community. As noted, corporations serve as aggregators of employee donations through federated charities such as the United Way. Recently, over $\$ 4$ billion was funneled from corporations to nonprofits in a single year by the local boards of over 1,300 community-based United Ways (Barman 2007). Furthermore, voluntarism is also most likely to be local. Corporate managers routinely serve on the boards of nonprofit organizations, and with few exceptions, these organizations are a commutable distance from corporate headquarters.

Indirect mechanisms of support include the spillover effects corporations provide through local jobs and wages, which further enhance funding and volunteer opportunities for nonprofits. Thus, simply having more corporate headquarters in a community makes for a more munificent environment for the growth of local nonprofits, even if the corporations themselves contribute nothing directly. Corporate headquarters provide relatively well-paid employment, a nexus for managerial talent, and a latent recruiting and organizing device. Just as the existence of a proximate base of suppliers enhances the prospects for start-ups in the instruments industry (Audia et al. 2006), and universities provide a fertile soil for biotechnology firms (Powell et al. 2005), corporations consequently create a resource base of funds and talent for nonprofits simply through their presence in the community.

Theoretically, we acknowledge this second mechanism, but in our empirical tests, we believe that our control variables account for much of its effect. Thus, the primary relationship that we propose here is that a dense population of local corporations in a community will lead to growth in both local social welfare- and eliteoriented nonprofits through direct effects of the corporations such as philanthropic giving, executive leadership, aggregation of donations, and employee volunteering.

Hypothesis 1 (H1). Greater local corporate density in U.S. communities will lead to growth in both (a) eliteoriented nonprofits and (b) social welfare-oriented nonprofits.

\section{Social Infrastructure of Communities}

A defining feature of communities and institutional fields is that their constituents are connected by social networks that influence the strength and direction of pressures toward conformity (Laumann et al. 1978). Putnam (1993) attributed the economic and political vibrancy of cities and regions in northern Italy-and their absence in southern Italy-to the networks and associated norms of their residents. Similarly, communities with dense networks among their organizations are particularly effective at promoting high levels of consistency in support of nonprofits (Marquis et al. 2007). Entrepreneurs can draw on the resources provided through these networks to build and grow nonprofit ventures to a sustainable size; they are more likely to be successful when these resources are more plentiful. Thus, we propose that nonprofit growth in a community will be greater when there is a more developed local social infrastructure, including social networks linking corporate decision makers, and when there are organizations facilitating cohesion among community leaders.

Local Network Cohesion. The relational network linking corporate decision makers has been shown empirically to encourage high levels of corporate involvement in nonprofits (Galaskiewicz 1997, Ostrower 2002). There are several reasons for this. First, corporate donors often direct their resources toward projects endorsed by their colleagues. This is seen in Columbus, 
$\mathrm{OH}$, for instance, where many corporations tend to support the same childrens' charities, following the lead of Wendy's founder Dave Thomas (Marquis et al. 2007). Second, networks enable mobilization around a common focus. Regular board meetings create a channel of communication among community business leaders that lowers the effort required by institutional entrepreneurs. The Atlanta Olympics, for instance, was enabled in part by a combination of dense ties among local business elites, such as the Coca-Cola Company, and entrepreneurial efforts by the local utility, Georgia Power (Glynn 2008). Third, dense networks allow for more effective moral suasion around philanthropy. The effectiveness of the Minneapolis-St. Paul "urban grants economy" rests in part on the fact that the tight-knit local business community can mobilize social pressure for compliance with local norms of support for nonprofits (Galaskiewicz 1985). Business leaders concerned with their social standing may feel required to contribute or face the judgment of their boardroom peers. Conversely, it is easier to be a free rider in a disconnected community, where norms are backed by little social sanction. These three arguments suggest that support for nonprofits will be greater in more densely connected business communities. Thus,

HYPOTHESIS 2 (H2). Greater network cohesion among local corporations will lead to growth in both (a) eliteoriented nonprofits and (b) social welfare-oriented nonprofits.

Local Institutions: Upper-Class Social Clubs. The presence of organizations that connect corporate and other decision makers within communities can also foster linkages between the corporate and nonprofit sectors and thus provide a channel for philanthropy. For instance, Galaskiewicz (1991) highlighted how local institutions were essential for focusing corporate elite's attention on nonprofit support. We highlight the role of an important local institution for elite cohesion, the upper-class social club (Domhoff 1967). Extensive research has suggested the importance of local upperclass clubs for the social cohesion of communities, particularly among elite members (Domhoff 1967, Kono et al. 1998, Marquis 2003). As Kono et al. (1998, pp. 867-868) noted, these "clubs are foci for elite interaction that provide institutionalized informal settings in which elites are socialized and socially controlled to adhere to normative business attitudes and behaviors." By providing a regular connecting point for elite corporate decision makers, such clubs allow the ready mobilization of resources in support of the nonprofit sector, which would lead to growth in nonprofits. Thus, we hypothesize the following.

HYPOTHESIS 3 (H3). The presence of an upper-class club will lead to growth in both (a) elite-oriented nonprofits and (b) social welfare-oriented nonprofits.

\section{Cultural Infrastructure of Communities}

In addition to social infrastructure, we propose that the cultural infrastructure of a community - its history and traditions-will also influence the growth of nonprofits. Nonprofits in communities whose cultures draw on long and focused traditions of philanthropy will be better able to access resources in support of particular causes and organizations. We propose that a community's embeddedness in an established regional culture (Hall 1992) and traditions enduring from the business community's founding period (Abzug and Siminoff 2004) may result in greater growth rates of nonprofits.

Regional Culture. A number of influential studies across a wide array of disciplines have shown that within the United States there is significant cultural variation across regions, suggesting that the prevalence or acceptability of organizational action may be geographically defined. For example, the political contributions of Sun Belt companies reflect a conservative culture, whereas companies from the North and Midwest are generally more politically centrist (Burris 1987). As well, social psychologists have shown that geography matters:

The North and the South, and the East and the West, diverge from one another, just as the city does from the country and the mountains from the coasts. These places differ not only in their geography or physical space, but also in their ideological landscape, or collective meaning space.

(Plaut et al. 2002, p. 160)

On a regional level, a number of studies have proposed significant variation in social and cultural behavior. Elazar's (1984) influential studies explaining regional variations in culture through the historical migratory patterns of different ethnic and religious groups showed that there is an individualist culture in the midwest and western United States, a moralistic and communitarian culture in New England and the Northern Plains, and a traditionalistic culture in the South.

With regard to nonprofit support and growth specifically, Hall (1992) distinguished different "cultures of trusteeship" that influenced the growth trajectory of local nonprofit sectors. In the central United States, a Midwestern federationalism emerged, based on the early example of Cleveland, where many smaller nonprofits banded together in federations to cooperate and attract support. In the Northeast, a civil privatism model developed based on the early example of Boston, where nonprofits were less organized but individually larger. Abzug and Siminoff (2004), in their empirical investigation of the nonprofit sectors of six cities over 60 years, found support for Hall's (1992) regional culture theory. Because we focus on the growth of larger elite-oriented and social welfare-oriented nonprofits that attract greater corporate interest, we center our attention on the northeastern United States.

Hypothesis $4(\mathrm{H} 4)$. Communities in the Northeast will have greater growth in (a) elite-oriented nonprofits 
and (b) social welfare-oriented nonprofits than communities in other regions.

Community Tradition. Existing theory and research suggest that patterns established early in a community's history tend to be enduring and to exert a contemporary influence. A particularly relevant period is the early 20th century, a time of substantial social change as an urban manufacturing-based economy replaced a rural and agrarian economy. The explosive growth of manufacturing during this time, coupled with a wave of finance-driven mergers, created national-scale public corporations and a new corporate and industrial geography in the United States in a relatively brief period. A number of cities grew to become industrial centers associated with particular industries-steel in Pittsburgh, automobiles in Detroit, and tires in Akron, for example. Traditions and standards created during this period continued to have long-lasting effects even decades later. For instance, Marquis (2003) showed that patterns of corporate governance, such as corporate board staffing, showed characteristic differences decades later, as new entrants mimicked the patterns of established local companies.

In the nonprofit sector, Hall (1987) theorized that early in the 20th century, the specter of socialism impelled a closer connection among community actors (governments, corporations, and nonprofits) that led to a flowering of nonprofit creation and growth. Many cities established new forms of philanthropic organization such as the community foundation or "community chests." To the extent that such traditions are enduring, such cities that established early local cultures encouraging nonprofit support are likely to have greater growth in nonprofits. Thus, we hypothesize the following.

Hypothesis 5 (H5). Communities with long-established corporate sectors will have greater growth in (a) elite-oriented nonprofits and (b) social welfareoriented nonprofits than communities with corporate sectors established later.

\section{Growth of Elite-Oriented Nonprofits}

We have argued that a community's nonprofit sector may gain from the presence of a large corporate population and from socially cohesive corporate networks and well-established cultural traditions of support for philanthropy. Each of these factors creates resources that can be drawn on by entrepreneurs to build sustainable nonprofit organizations. However, we propose that a disproportionate level of resources from the large corporate sector will be channeled toward elite-oriented nonprofits (but not social welfare-oriented nonprofits) to the extent that the corporate sector is well connected and united by shared cultural norms and traditions. In other words, we predict that there will be an interaction between the density of the corporate sector and the elements of the community's social and cognitive infrastructure that we have described such that elite nonprofits will grow to a greater extent than social welfare nonprofits. In short, our argument for this relationship has two features. First, for a variety of reasons, corporate elites may have disproportionate interest in elite nonprofits. Second, they may be more likely to be able to act on those interests when they are in locales that provide greater social and cultural support.

Prior research has shown that elite-oriented nonprofits, such as those in the arts, culture, and private education, have long enjoyed the patronage of the wealthy and, more recently, those in the corporate sector. This suggests that contests for social status, at the level of both the individual and the organization, have played a central part in propelling the growth of such elite-oriented nonprofits from the Gilded Age in the second half of the 1800s (DiMaggio and Anheier 1990) to the current era, in which corporations provide much of the support for such nonprofits (Odendahl 1990). As Galaskiewicz et al. (2006, p. 246) summarized, donors particularly want to be associated with prestigious cultural institutions because "the causes they supported defined their own social status." Furthermore, such nonprofits disproportionately raise the local standard of living for the corporate elites because they are more likely to enjoy their benefits. Thus, although corporations in the Twin Cities of Minneapolis-St. Paul are lauded for their generous support of nonprofits, less often noted is the extent to which their charity is channeled to arts and culture organizations, and not social welfare groups (Marquis et al. 2007). Because such elite-oriented nonprofits provide a disproportionate benefit to corporations and their executives, we believe that their support will be enhanced in communities with social and cultural infrastructures that validate this support.

Generally speaking, local social and cultural infrastructures enable the spread of information about local needs and mobilize support across a wide variety of nonprofit sectors (Galaskiewicz 1997). However, a number of prior studies have also shown that greater social and cultural cohesion among elites also sets the stage for more self-interested action, which partially explains support of elite-oriented nonprofits. For instance, scholars have shown that states were quicker to pass antitakeover laws favored by corporate elites when those elites were densely connected through common board memberships (Vogus and Davis 2005). Similarly, political contributions by corporations were more alike to the extent that their executives served on bank boards together (Mizruchi 1989). We emphasize that in both cases, action was not a simply a result of the size of the corporate sector but a combination of the size of the sector, its social organization, and agreement on common interests. Thus, in addition to aiding the growth 
of nonprofit sectors generally, we believe that a locally supportive social infrastructure will positively moderate the relationship between corporations and elite-oriented nonprofits.

Furthermore, we also believe that the cultural infrastructure will positively interact with corporate density, resulting in greater gains to elite-oriented nonprofits. As previously noted, prior research by Hall $(1987,1992)$ identifies an interrelated set of regional and historical processes that led to greater institutionalization of nonprofit support in the Northeast and long-standing communities. Building on this research, Abzug and Simonoff (2004) showed that nonprofits in the northeastern cities of Boston and Philadelphia, in particular, had a greater elite focus than in the midwestern, southern, and western cities they studied. This suggests that in such locales, support of elite-oriented nonprofits such as art museums, symphonies, and private educational institutions may be more justifiable to local stakeholders.

These interrelated arguments imply that elite-oriented nonprofits may be more amenable to corporate interests and that some locales may provide greater institutional support-whether through social infrastructure or broader cultural legitimacy-for corporate support of these nonprofits. This suggests that the existence of a large corporate sector, combined with dense networks and supportive cultures, will enhance the growth of eliteoriented nonprofits relative to other kinds of nonprofits.

Hypothesis 6 (H6). The positive effect of corporate density on the growth of local elite-oriented nonprofit organizations will be stronger in communities with social infrastructures characterized by (a) more cohesive elite networks and (b) upper-class social clubs.

HyPOTHESIS 7 (H7). The positive effect of corporate density on the growth of local elite-oriented nonprofit organizations will be stronger in communities with cultural infrastructures characterized by (a) a location in the Northeast and (b) long-established corporate sectors.

\section{Data and Methods}

\section{Unit of Analysis and Sample}

Our concept of community implies a significant population center within a relatively compact geographic area-in essence, a commutable distance. We operationalize community by using the Office of Management and Budget's Core Based Statistical Areas (CBSAs). ${ }^{4}$ The U.S. Census Bureau (2007) defines a CBSA as a "core area containing a large population nucleus, together with adjacent communities having a high degree of economic and social integration with that core." For example, the Chicago CBSA includes Cook County as well as eight other counties that surround it, thereby capturing companies headquartered in the greater Chicago area (e.g., Sears in Hoffman Estates, Abbott Laboratories in Abbott Park). Because our theory and hypotheses relate to the density of corporations and, in particular, the degree of connection among their elites, we sampled all U.S. communities above a minimum threshold of corporate density. We include 100 communities with more than five locally headquartered public corporations in 1987, 1992, 1997, and 2002. "Public corporations" were those traded on either the New York Stock Exchange or the NASDAQ National Market and that were covered by Compact Disclosure, a sampling frame that ranged from 4,000 to 6,100 companies over the course of our sample period.

\section{Dependent Variables}

To operationalize our two dependent variableselite-oriented nonprofits and social-welfare oriented nonprofits-we collected data on 501(c)(3) operating nonprofits from the National Center for Charitable Statistics (NCCS) at the Urban Institute. The NCCS compiles data from annual filings of IRS Form 990 for all nonprofits above a threshold of $\$ 10$ million in assets (increased to $\$ 30$ million after 2001$)^{5}$ and creates a database known as the Statistics of Income (SOI). These data identify the headquarters of given nonprofits that we use to aggregate based on CBSAs matching the procedure described above for corporate headquarters. The number of organizations covered in the database grew from about 6,000 in 1987 to roughly 10,000 in 2003. Contemporaneous measures of the size of the nonprofit population are likely to reflect a number of unobserved factors. To address this, our modeling procedure (discussed in more detail below) assesses the growth in the number of elite-oriented and social welfare nonprofits to best capture the effects of our hypothesized variables. For each panel, we collected data on organizations for both the focal panel year and the subsequent year to track year-upon-year growth. For instance, for the 2002 panel, we collected separate counts of 2002 organizations and 2003 organizations.

The NCCS SOI data are widely regarded as the gold standard in the study of nonprofits (Boris and Steuerle 2006). They do, however, introduce a potential for bias because they exclude organizations below a minimum size threshold, creating a conservative measure of the magnitude of the nonprofit population in a given community. It is undoubtedly true that nonprofits are undercounted by the NCCS: there were roughly 200,000 tax-exempt organizations with paid employees in 2002 (Salamon and Sokolowski 2005) and many times that number of registered nonprofits with minimal operations and no paid employees, because it is relatively simple as a legal matter to register a nonprofit organization. Filing the paperwork to create a nonprofit is a low hurdle, analogous to creating a corporation (which can easily be done online with a credit card). So by imposing a 
minimum size cutoff, we ensure that we are counting organizations with nontrivial operations that are likely to have the most significant impact on their communities. Moreover, the $\$ 10$ million threshold is actually quite modest; for comparison purposes, in every year our sampling frame included far more nonprofits than corporations. Furthermore, we believe that it is consequential that the NCCS, the primary data source on the nonprofit industry, uses this value as a cutoff when creating its database and distributing data. ${ }^{6}$

To capture distinctions among the different types of nonprofits on which we focus, we draw on the typology developed by the Urban Institute-The National Taxonomy of Exempt Entities (NTEE). The NTEE system divides nonprofits into 26 major categories with over 300 subcategories. For each of these categories and subcategories, we classified the nonprofit type as elite-oriented, social welfare-oriented, or other. Elite-oriented nonprofits include the categories of arts, culture and humanities, and philanthropy as well as recreation and sports subcategories that would benefit the elite such as golf, equestrian, and major sporting events such as organizations hosting the Olympics (Glynn 2008). For example, in Boston these types of elite nonprofits include organizations such as the Boston Ballet and Milton Academy. Social welfare-oriented (social welfare, for short) nonprofits include the categories of mental health, employment, housing, health care, public safety, youth development, human services, civil rights, public benefit, food and nutrition subcategories that relate to providing meals for homeless or homebound populations, and recreation and community improvement subcategories that are broadly oriented. For example, in Boston these types of nonprofits include organizations such as local hospitals (UMass Memorial HealthCare), transition homes for the abused (Bridge Over Troubled Waters), vocational training centers (Vocational Adjustment Center), elder care organizations (Elder Housing), and many other organizations that focus on community needs. The residual category, other, includes a variety of nonprofits focused on scientific, professional, or other issues that are not directed specifically to the local community. For example, in Boston this includes medical research (Foundation for Neurological Diseases), international affairs (Oxfam-America), environmental (National Religious Partnership for the Environment), and other similar types of organizations. Although the "other" nonprofits are not included in main analyses that test the hypotheses, we did conduct supplementary analysis including these. This supplementary analysis is discussed in the Results section.

\section{Independent Variables}

Corporate Density. Our sampling frame included all U.S.-based corporations listed on the two major U.S. stock markets, the New York Stock Exchange and NASDAQ, and which were covered by disclosure in each of our four panel years. This included over 4,000 companies in 1987 and 1992, over 6,000 in 1997, and over 4,800 in 2002 . For each corporation, we assembled data on headquarters location, industry, sales and other financial measures, employment, a variety of financial measures, and the composition of the board of directors. We measured corporate density (see H1) as the count of corporations that are headquartered in a CBSA in a given year (logged to correct for a skewed distribution). ${ }^{7}$

Social Infrastructure. To calculate network measures of local corporate cohesion, we constructed network data sets based on shared directors among the boards of all firms in our corporate sampling frame for each panel year (see Mizruchi 1996 for a review). We used extensive computerized and manual data cleaning procedures to ensure consistency and accuracy in coverage across boards and over time, which yielded a master data set that includes a total of 152,466 director-year observations across our four panel years. Our measure of local network cohesion (see $\mathrm{H} 2$ and $\mathrm{H} 6 \mathrm{a}$ ) was mean local degree-that is, the average number of network ties each firm in a CBSA maintained with other firms in its CBSA. This number is high to the extent that local companies recruit directors that also serve on the boards of other local companies. Extensive prior research shows that shared directors are an important mechanism for the spread of information among corporate boards and for the enforcement of local norms (Mizruchi 1996, Marquis, 2003). ${ }^{8}$ We used the upper-class club (see H3 and H6b) list established by Domhoff (1967; see Kono et al. 1998, note 2, for Domhoff's process) to determine the presence of upper-class clubs in each CBSA.

Cultural Infrastructure. We include a dummy variable to assess a community's regional culture (see H4 and H7a), indicating whether the region is the Northeast, consistent with other researchers who have studied effects of regional culture on the nonprofit sector (Elazar 1984, Hall 1992, Abzug and Simonoff 2004). Following Marquis (2003), we measure the early establishment of the business community (see $\mathrm{H} 5$ and $\mathrm{H} 7 \mathrm{~b}$ ) using the number of incorporated firms in each city in 1905 from the Census of Manufactures (U.S. Bureau of the Census 1906). Because of extreme values, this variable was logged.

\section{Control Variables}

We include in the models a number of governmental, political, socioeconomic, and demographic variables that could also affect nonprofit growth. Regarding governmental and political factors, a number of studies have suggested that city governments may coalesce corporate interests around key needs or issues (Marquis et al. 2007). During our sample period, following changes by 
the Reagan administration, governments became more proactive in "buying" versus "making" social and welfare services, which led to a governmental outsourcing trend that directly influenced the growth of nonprofits (Salamon 1987, Bielefeld and Corbin 1996). As control variables, we include a number of variables to account for these processes. We operationalize the size of government as total governmental revenue for each of our CBSAs, collected from the Census of Governments, which is taken every five years in years ending in 2 and 7 . We include an indicator of whether our city was a capital city. For each of our city-years, we also include whether there is Republican leadership to capture the ideology of local political leaders that are making the key local social service provisions.

Another major perspective on nonprofit growth is that they arise out of need. For instance, higher levels of poverty might prompt the creation of nonprofit educational or health-care services for low-income clients (Weisbrod 1998). To account for this, we gathered data on the economic well-being of the communities and their residents. From the U.S. Census, we gathered data on local income levels (wages per job); income growth, which we calculated as the percentage change in local income in the previous five years; and total population to capture the level of economic well-being and overall size of the community. Because a number of our theories focus on historical factors in cities and because such processes are connected to the development of the manufacturing centers in the United States, we include a variable that measures the percent manufacturing - that is, the proportion of locally headquartered firms in Standard Industrial Classification groups 2 and 3. Another important consideration is the degree to which corporations' business operations are focused locally or more broadly. To tap the degree to which corporations in a community are globally oriented, we calculated the average percentage of global sales, i.e., sales outside the United States for locally headquartered businesses. These data were gathered from the Compustat geographic segment data as compiled by the Wharton Research Data Service.

\section{Models}

We test our hypotheses with a lagged panel design to assess changes in our dependent variables using random effects regression to control for the fact that we have multiple observations per community. We have four panels of data for all of our independent variables in 1987, 1992, 1997, and 2002. Because we are interested in assessing change in our dependent variables, we include dependent variables from period $t+1$ (Kessler and Greenberg 1981). For example, the structure of the model for elite-oriented nonprofits is as follows:

$$
\begin{aligned}
& \text { (Elite-oriented nonprofits })_{t+1} \\
& \quad=B_{0}+(\text { Elite-oriented nonprofits })_{t}
\end{aligned}
$$

$$
\begin{aligned}
& +(\text { Corporate density })_{t} \\
& +(\text { Corporate density } * \text { Network cohesion })_{t} \\
& +\cdots+(\text { Controls })_{t}+U
\end{aligned}
$$

As the equation illustrates, when the 2002 values are the independent variables, the dependent variables are 2003 values. In these models, because the equation is effectively measuring the change in the dependent variable from $t$ to $t+1$, the independent variables are interpreted as predictors of change in the dependent variable.

\section{Results}

Table 1 presents the correlations and descriptive statistics for variables in all of our models. Because there are high correlations between some of our variables, we ran diagnostics to ensure that our results are not affected by multicollinearity. The mean variance inflation factor (VIF) across all of our models is well below 10, the suggested threshold point; thus, multicollinearity appears not to be a serious threat.

We present tests of our hypotheses in Tables 2 and 3, which model the effects of the hypothesized variables on the two dependent variables of elite-oriented and social welfare-oriented nonprofits, respectively. Each table has 11 models, with the first 6 models in each table focusing on the main effect predictions and the second 5 models addressing the interaction effects. Models 1-5 are mainly informational, showing the effects of each predicted variable with only the control variables. Model 6 presents full models with all main effects, upon which we will base our conclusions for Hypotheses 1-5. Models 7-10 present models with the interaction effects that we hypothesize in $\mathrm{H} 6$ and H7; Model 11 is a full model with all variables. In interpreting the significance of the interaction effects, we draw on both the full and reduced models.

Hypothesis 1 predicted that having a greater density of locally headquartered firms would lead to growth in both social welfare-oriented and elite-oriented nonprofits. Model 6 in Tables 2 and 3 supports this prediction. The coefficients in these models are highly significant and thus provide support for hypotheses concerning both elite-oriented (H1a) and social welfare-oriented (H1b) nonprofits. Thus, communities with more corporate headquarters not only have more local nonprofits at any given time but also see greater growth in the number of local nonprofits over time. This is consistent with the idea that local corporations provide ambient resources for nonprofit entrepreneurs. Although we earlier acknowledged both direct and indirect mechanisms connecting corporate density with nonprofit growth, our control variables, such as local income and income growth, mostly account for these indirect processes. Thus, these results lead us to conclude that corporate presence directly leads to growth in a diverse array of 


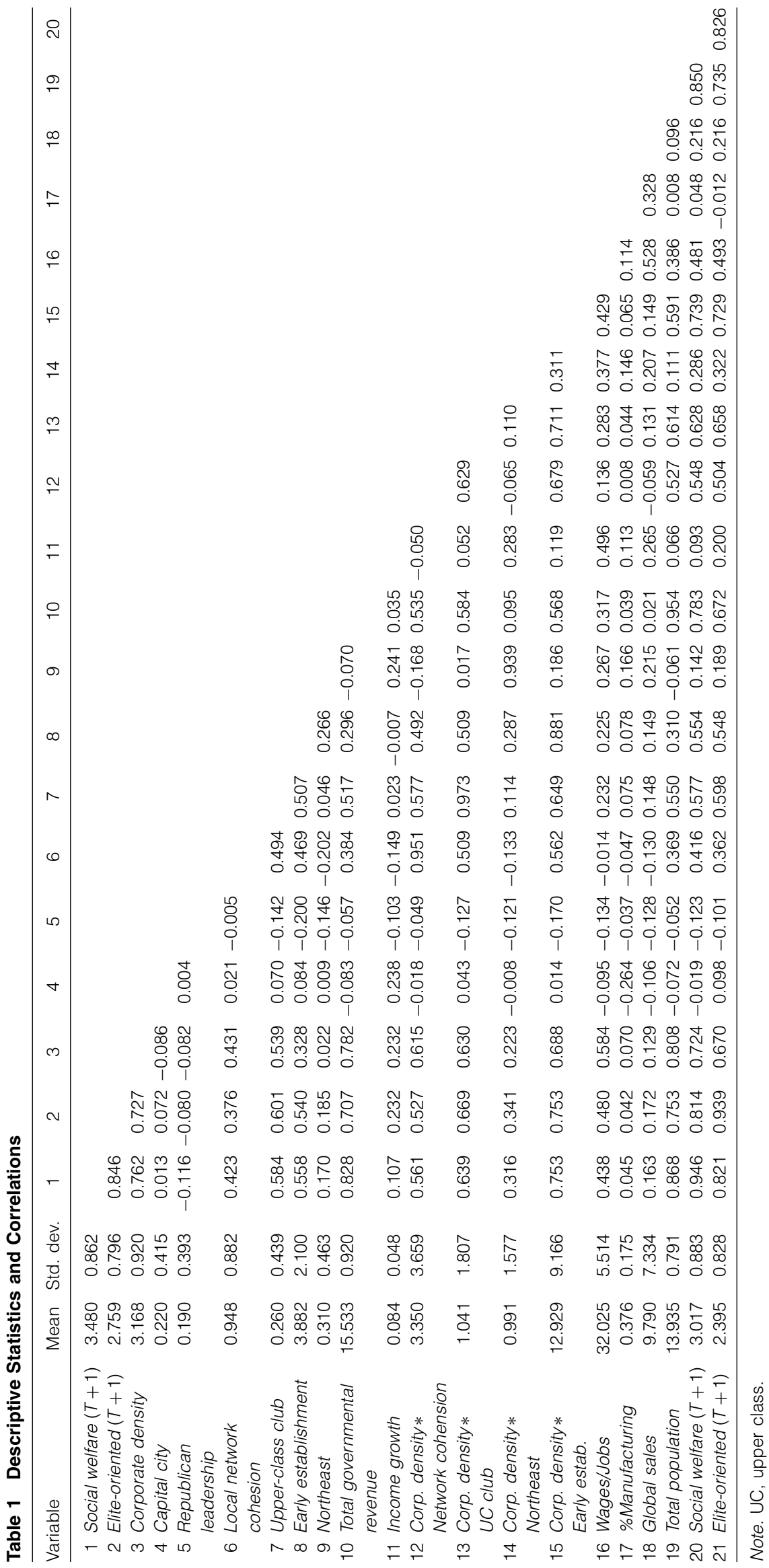




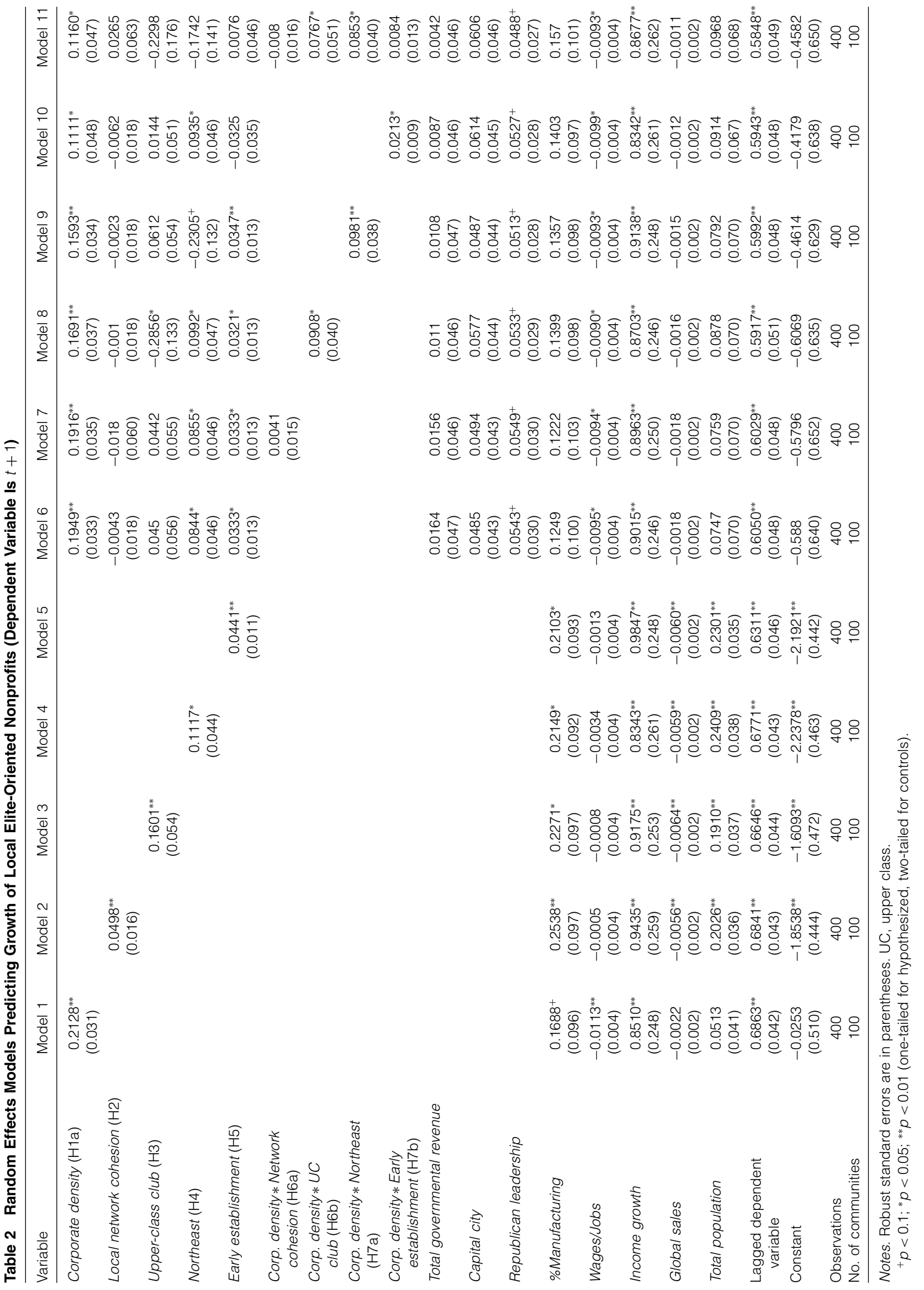




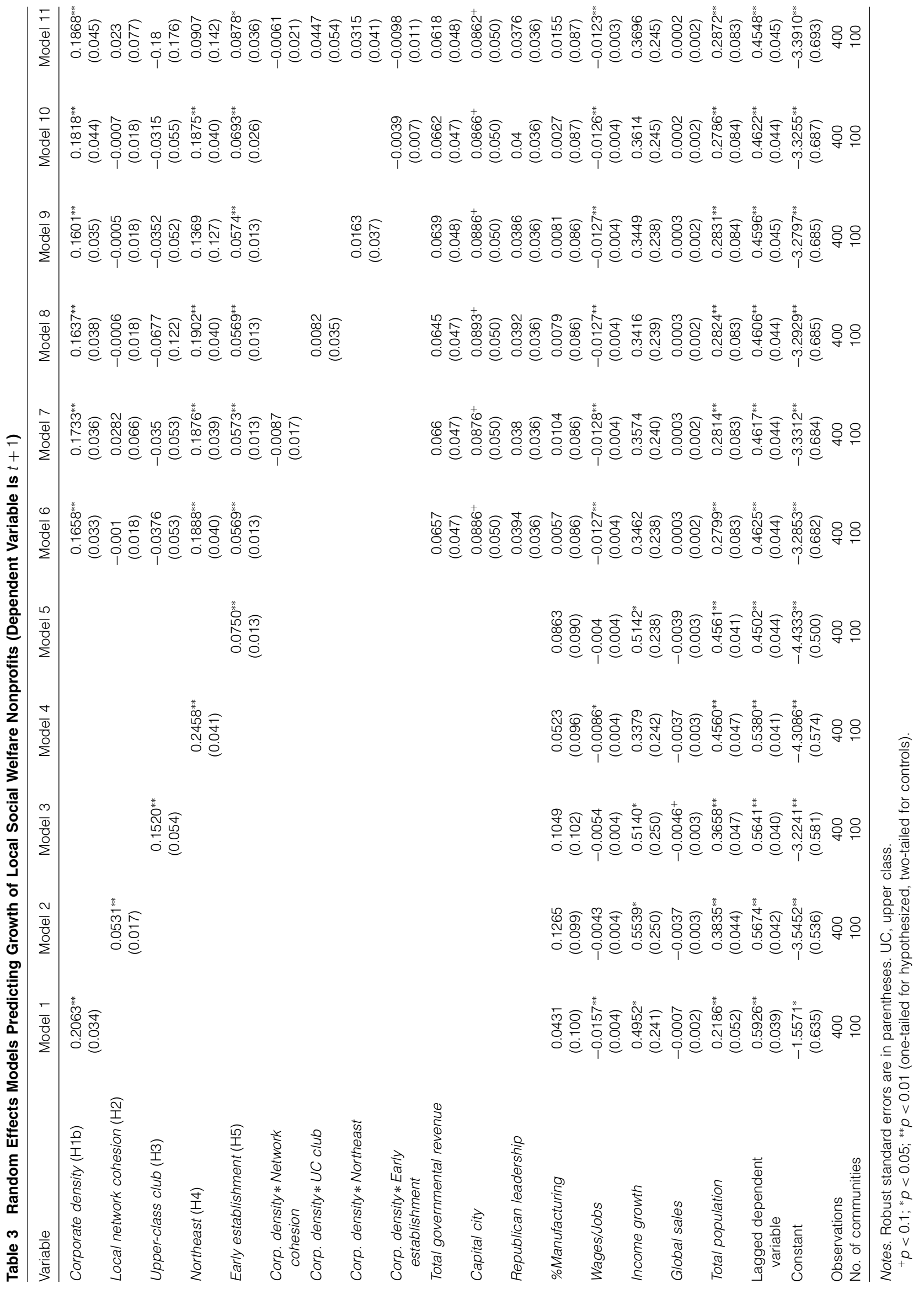


nonprofits, even net of many other political, social, and economic features of cities.

The social infrastructure factors we predicted in Hypotheses 2 and 3 do not find strong support. Although both of these variables were statistically significant predictors of both types of nonprofits in the reduced models (models 2 and 3 in Tables 2 and 3), neither was statistically significant when entered with the full contingent of independent variables. Hypotheses 4 and 5, regarding the cultural processes, however, were strongly supported across both types of nonprofits, suggesting that communities in the northeastern United States and communities with an early business establishment experienced higher nonprofit growth rates than others. These findings imply that communities with long-established business communities, and particularly those with cultural traditions of support for the nonprofit sector, provide more fertile soil for nonprofit entrepreneurs than younger communities lacking in such traditions.

To uncover some of the moderating effects of local social and cultural infrastructure on the growth of eliteoriented nonprofits, we tested the series of interaction effects predicted in Hypotheses 6 and 7. Models 7-11 in Table 2 present the results. Although Hypothesis $6 \mathrm{a}$ predicting a moderating effect for networks was not supported, we do find support for Hypotheses 6b, 7a, and $7 \mathrm{~b}$; that is, the growth of elite-oriented nonprofits is greater to the extent that corporate density is accompanied by the presence of upper-class clubs (6b), a location in the Northeast (7a), and a long-established local business community (7b). For comparison purposes, in Table 3 we present models that show the interactive effects of these same independent variables on the growth of social welfare-oriented nonprofits. Unlike the elite-oriented nonprofits, none of the interactions is statistically significant. In combination, these results provide evidence that a well-organized and well-established business community with strong cultural norms is particularly advantageous for the growth of elite-oriented nonprofits, whereas it provides little incremental advantage for social welfare nonprofits.

We also conducted a series of robustness checks (available from the authors upon request) to provide additional support for our hypothesized mechanisms and to rule out alternative explanations. First, we conducted two different sets of analyses where we specified key independent variables differently. One approach implemented our models examining just the total level of nonprofits as opposed to a change model when we include a lagged dependent variable. Results not including the lagged dependent variable were quite similar to those presented here. In addition, because our focus is on local nonprofits, we ran our analyses excluding Washington D.C. and New York, the U.S. headquarters of most international nonprofits, to make sure those observations were not unduly biasing our results. These results were again quite similar to what we report.

A key feature of our approach was unpacking how corporations influence different types of nonprofit organizations: elite-oriented, social welfare-oriented, and other. However, one concern may be that we have inadvertently identified processes that would influence all types of organizations, not just the types of nonprofits that we identify. To investigate this possibility, we ran analogous models using as our dependent variable the residual category "other nonprofits," which tend to benefit industry-specific, national, or global concerns rather than the local community. In these analyses (available from the authors upon request), none of the hypothesized variables found to be significant in the models we present (see Tables 2 and 3) significantly affect these "other" nonprofits. We are heartened by this nonsignificant result and take this as evidence that our categorization of nonprofit types and theorization of their influences have usefully identified important nonprofit dimensions and, in particular, the processes by which corporations and communities' institutional infrastructure affect the local nonprofit sector.

A final robustness check uses fixed effects to model the influence of time-varying characteristics of communities on nonprofit growth to determine whether our

Table 4 Fixed Effects Models Predicting Local Elite-Oriented and Social Welfare-Oriented Nonprofits

\begin{tabular}{|c|c|c|}
\hline & Elite-oriented & $\begin{array}{c}\text { Social } \\
\text { welfare-oriented }\end{array}$ \\
\hline Corporate density & $\begin{array}{l}0.1553^{* *} \\
(0.0470)\end{array}$ & $\begin{array}{l}0.1444^{* *} \\
(0.0430)\end{array}$ \\
\hline Local network cohesion & $\begin{array}{c}0.0114 \\
(0.0230)\end{array}$ & $\begin{array}{c}0.0217 \\
(0.0210)\end{array}$ \\
\hline Total governmental revenue & $\begin{array}{r}-0.1617^{*} \\
(0.0740)\end{array}$ & $\begin{array}{c}-0.2240^{* *} \\
(0.0670)\end{array}$ \\
\hline Republican leadership & $\begin{array}{c}0.034 \\
(0.0340)\end{array}$ & $\begin{array}{c}0.0156 \\
(0.0310)\end{array}$ \\
\hline$\%$ Manufacturing & $\begin{array}{c}0.054 \\
(0.1140)\end{array}$ & $\begin{array}{c}0.1502 \\
(0.1030)\end{array}$ \\
\hline Wages/Jobs & $\begin{array}{r}0.0111^{*} \\
(0.0050)\end{array}$ & $\begin{array}{c}0.004 \\
(0.0050)\end{array}$ \\
\hline Income growth & $\begin{array}{r}0.7548^{*} \\
(0.2650)\end{array}$ & $\begin{array}{c}0.0718 \\
(0.2400)\end{array}$ \\
\hline Global sales & $\begin{array}{c}0.0025 \\
(0.0020)\end{array}$ & $\begin{array}{c}0.0002 \\
(0.0020)\end{array}$ \\
\hline Total population & $\begin{array}{c}0.1481 \\
(0.1390)\end{array}$ & $\begin{array}{c}0.3096^{*} \\
(0.1260)\end{array}$ \\
\hline Constant & $\begin{array}{c}2.232 \\
(2.088)\end{array}$ & $\begin{array}{c}1.9721 \\
(1.890)\end{array}$ \\
\hline Observations & 400 & 400 \\
\hline No. of communities & 100 & 100 \\
\hline
\end{tabular}

Note. Robust standard errors are in parentheses.

${ }^{+} p<0.1$; ${ }^{*} p<0.05$; ** $p<0.01$ (one-tailed for hypothesized, twotailed for controls) 
results could have been influenced by unobserved heterogeneity between communities. A limitation, however, is that a fixed effects approach does not allow for investigating the influence of factors such as regional location or early establishment that vary across but not within communities over time. Because fixed effects models implicitly control for all time-invariant differences (including unobserved ones) between communities, these models show how changes in the independent variables within a given community lead to changes in the dependent variables in that community. Thus, it allows us to more rigorously document a key mechanism we propose, that as the number of corporations in a community grows so too does the nonprofit sector. We present these analyses in Table 4. Although we are unable to include many of our hypothesized factors that are fixed community characteristics (i.e., regional location, upper-class club, and early establishment), the results show that changes in corporate density in a community influence changes in both elite-oriented and social welfare-oriented nonprofits in communities.

\section{Discussion and Conclusions}

A classic debate in organization theory has centered on the question, "What are the consequences of the existence of organizations?" (Hinings and Greenwood 2002, p. 411). This theme was the focus of early theorists such as Weber (1964) and Michels (1962), who sought to understand how the rise of large organizations shaped social relations and society more generally. This stream of research has largely disappeared, perhaps because, as Stern and Barley (1996, p. 152) suggested, "Larger issues [of societal consequences] are not only difficult to address, but... exploring them leads one astray from developing organizational theory." We believe that a major contribution of our research is to reintroduce the study of broader social issues back into organizational theory.

We studied how locally headquartered corporations influenced the growth of two different types of nonprofit organizations - those oriented to the elite and those focused more broadly on social welfare-in the 100 largest U.S. communities from 1987 to 2002. Our results show a consistent pattern in the effects of a number of community-level factors - corporate density, regional location, and historical factors-on the growth of both types of community nonprofits. Moreover, we found that the presence of supportive social and cultural infrastructure significantly moderated the effects of corporate density on elite-oriented nonprofits but not on social welfare-oriented nonprofits. In other words, businesses are good for nonprofits, but they are especially good for nonprofits that directly benefit the corporate elite. Below we discuss this study's contributions to understanding communities as institutional fields and the role of the corporation in society.

\section{Communities as Institutional Fields}

Recent work in organization theory has seen a growing theoretical tension between studies that emphasize universalizing tendencies that transcend place and those that emphasize the critical influence of local geography on organizational behavior (Marquis and Battilana 2009, Marquis et al. 2011). On the one hand, modern transportation and communication systems seem to render geographical boundaries increasingly irrelevant, as organizational fields partake of global processes that spread homogeneity around the world (Scott 2001). On the other hand, geographic communities determine access to resources for organizational creation (Audia et al. 2006), shape the dynamics of competition for labor and consumers (Sorenson and Audia 2000), influence decisions such as whether to downsize (Greenwood et al. 2010), and provide norms of strategy (Lounsbury 2007) and governance (Marquis 2003). Thus, despite the trend showing evolution from particularism to universalism (e.g., Warren 1967, Robertson and Khondker 1998, Sorge 2005), the idiosyncrasies of community continue to shape organizational behavior in critical ways, from the norms and networks that promote industrial reinvention in Silicon Valley (Saxenian 1994) to the urban amenities and diversity that attract the creative class and its employers (Florida 2002).

We propose that a way to conceptually unpack this tension is to conceive of communities as institutional fields, which highlights the multisectoral processes and interactions we demonstrate. That is, community is not just about the spatial bounds of markets, the proximity of corporate actors, or where political boundaries are defined. Rather, community entails important social and cultural factors shaping organizational behavior. The means by which communities have their effects can be dimensionalized in terms of their character as fields, i.e., the nature of their social and organizational infrastructure and cultural-cognitive understandings. Prior studies of nonprofits have often examined specific cities (e.g., Minneapolis, Atlanta) or types of nonprofits such as arts (DiMaggio 1991) or health services (Bielefeld and Corbin 1996). Similarly, prior studies of geographyindependent fields have often been, in effect, case studies of environmentalism (Hoffman 1999), biotechnology (Powell et al. 2005), or health care (Scott et al. 2000). By combining these approaches, we show that the effect of these community pressures is to focus the attention of organizational actors locally even as business expands globally, with consequences for the growth of two important types of nonprofits.

Recognizing the geographic community as an organizational field overcomes one of the prominent limitations of institutional research, that of focusing on a single industry or sector. As DiMaggio and Powell (1983, p. 148) initially conceptualized the organizational field-"as a recognized area of institutional life"-they 
pointed out that the "virtue in this unit of analysis [is]...that it directs our attention not simply to competing firms...or to networks of organizations that actually interact... but to the totality of relevant actors" (emphasis added). By focusing on the level of the local community, we expanded the set of field actors to include for-profits, nonprofits, and other organizations, thus revealing both the direct and indirect effects of their membership in this field, as well as allowing a comparative approach across multiple communities.

Our more general contributions to institutional theory include showing how historical forces and the legacy of elite interactions continue to shape not only social outcomes but also interorganizational interactions within community fields. To a surprising extent, the historical circumstances of a city's growth had lingering effects on its present-day community dynamics. For both types of nonprofits, early established cities were more likely to have nonprofit growth. Consistent with Hall (1987) and Marquis (2003), we speculate that the norms of civic engagement established by business leaders in the early period of large-scale industrialization cast a long shadow. This enduring legacy may provide some solace to well-established communities that lose business; norms of civic engagement seem to run deep in spite of such exits. For instance, although Boston lost three of its largest headquartered firms early in the 2000s (Gillette, FleetBoston, and John Hancock), early reports suggest that nonprofit giving had not declined (Talcott 2005). The process of how such traditions endure is described in an article on corporate giving in Minneapolis:

When a new chief executive came to town, other chief executives would sit him down and explain how things were done in the Twin Cities. In 1988 when the British firm Grand Metropolitan bought Pillsbury in a $\$ 5$ billion hostile takeover, people worried that raiders from overseas would cut back on the company's giving, which was at the 2 percent level. Instead, the city's corporate leaders met with the Grand Met representatives ... and explained what... (our) culture was.

(Nocera 2007)

As a result, Pillsbury maintained its $2 \%$ giving.

\section{The Corporation and Social Outcomes}

Our results indicate that future research on how organizations affect society can gain traction by examining processes at the community level. We found that communities that had a large population of corporate headquarters saw enhanced growth of both types of nonprofit organizations, but we anticipate that corporations can have a broad spectrum of influences on their local communities.

At a more practical level, we also contribute to understanding how and where nonprofit organizations grow. Given that this sector employs almost $10 \%$ of the U.S. workforce, it is surprising that it does not attract more research attention from organizational theorists. Our results on the prevalence of corporate headquarters in U.S. cities significantly promoting the overall vitality of key nonprofit sectors can provide some guidance to community leaders. Whereas prior research has implicated generational changes and individuals choices in civil society changes (Putnam 2000), our results suggest that individuals' choices are made against a set of constraints shaped by the society and economy around them. Even in a postindustrial economy with extensive globalization, local community still matters: companies support social welfare and elite-oriented nonprofits closest to home. Chicago's concerted effort to attract Boeing, with its promise of only 500 additional jobs, thus appears prescient, as our analyses suggest that the strategy of attracting corporate headquarters may make sense for communities as many important spillovers to community nonprofits would ensue.

However, by specifically identifying the elite nature of some nonprofits, our findings also seem to warrant a potentially skeptical stance with regard to corporate support of nonprofits in the United States. As our interaction effects showed, the impact of corporate density was magnified in cities with an elite characterized by cohesive social organization and supportive cultural features-but only in the case of elite-oriented nonprofits, i.e., those focused on arts, culture, and private education. Social welfare-oriented organizations, in contrast, saw no such additional benefit. Our results are thus generally consistent with speculation in the large extant literature on nonprofits indicating that philanthropy may actually be a vehicle to benefit elite interests (e.g., Ostrander 1984, DiMaggio and Anheier 1990, Ostrower 1995). We go beyond this prior work, looking across a large number of communities and demonstrating that corporate effects on elite-oriented nonprofits are enhanced to the extent that there is a community infrastructure that seems to organize and validate the elite. Thus, we add an important caveat to prevailing wisdom: corporations may be prone to "responsibility with a payoff," but this is realized primarily when infrastructure for collective coordination and mobilization is in place. At a more general level, these findings suggest that even within institutional fields with strong centripetal forces, different kinds of actors can be disproportionally influential when supporting social and cultural structures exist.

In conclusion, these results provide a nuanced picture of interorganizational, multisector dynamics at the community level, and they suggest that there is a subtle interplay among corporate headquarters and mediating social and cultural institutions for elite cohesion worthy of further investigation. Local organizations, society, culture, and government are closely interrelated in dynamic fields; our findings reinforce this and intimate the usefulness of studying their interaction. We believe 
that if organizational scholars are to shift their concerns to larger societal issues, focusing more explicitly on how corporations affect society (Hinings and Greenwood 2002), our results indicate that the community is an appropriate and useful site for doing so. The vibrancy of nonprofits within a community represents one of the most direct indicators of the quality of life in that community, from the availability of education and the arts to the nature of the social safety net. The findings reported here document that the local organizational field-its size, its composition, and the ways its constituents interact within a community-is perhaps the most proximate factor behind the vibrancy of the nonprofit sector. Thus, there are both relatively straight as well as winding paths leading from organizations to quality of life within communities, and these different paths merit further study.

\section{Acknowledgments}

The authors thank senior editor Pam Tolbert and the anonymous reviewers for their guidance and Julie Battilana, Alnoor Ebrahim, Matthew Lee, Mike Lounsbury, Joshua Margolis, Mark Mizruchi, Don Palmer, and András Tilcsik for helpful comments on earlier drafts of the paper. They also thank Debbie Strumski and Sarah Woolverton for research assistance, the Harvard Business School Division of Research for funding to collect these data, and the Boston College Winston Center for Leadership and Ethics and the Joseph F. Cotter Professorship for support.

\section{Endnotes}

${ }^{1}$ Defined as Core Based Statistical Areas (CBSAs), which we discuss in the Data and Methods section.

${ }^{2}$ These years were chosen to match the U.S. Economic Census surveys, which provide several of our independent variablessee http://www.census.gov/econ/census02.

${ }^{3} \mathrm{We}$ acknowledge that some nonprofits that provide services to the poor may nonetheless have a role in maintaining the local elite in that wealthy residents dominate their boards and service on those boards is a mark of recognition and achievement. ${ }^{4}$ This is a revised system that builds on the prior Metropolitan Statistical Areas (MSA) system. Our measurement is as of November 2004 definitions. To make sure all of our variables account for spatial changes in CBSAs over time, the measurement of all of our variables, even those that extend back to 1987 , is based on this more recent geographic definition. To accomplish this, for all of our variables, we obtained the underlying county data and aggregated these to CBSA based on the November 2004 definitions.

${ }^{5}$ This discontinuity is unfortunate; however, we feel that it does not impact or bias our analyses. First, as we discuss, our panel design focuses on modeling the growth of the local sectors between $t-1$ and $t$. Thus, the discontinuity is between panels and does not impact the analyses of each specific year (e.g., the analyses of growth between 2002 and 2003 compares comparable organizations). Second, we conducted numerous robustness checks, such as running the data without the latest panel and inserting dummy variables-none of which altered the presented results.

${ }^{6} \mathrm{~A}$ second concern is the possibility that the population size might change because of nonprofits moving above (or below) the $\$ 10$ million threshold. In fact, however, across both eliteoriented and social welfare-nonprofits, we find that over $90 \%$ of organizations that appear in one year also appear in the following panel. Thus, nearly all the variation in the sample is due to the addition of new organizations.

${ }^{7}$ Alternative specifications could include total corporate sales in a community or total corporate profitability in a community. We chose to use corporate density for a number of reasons. First, we believe that it is conceptually consistent with our focus on growth in nonprofit density and our discussion of the importance of the changing demography of corporations. For instance, if one were to focus on sales, this would overemphasize cities that have a number of large corporations, e.g., Detroit, and obscure the effects of the vibrancy of smaller and midsize public company growth that we believe are important processes that relate to nonprofit growth. Results, however, are very similar to those reported when using total local sales. Additionally, although there may be a relationship between corporate profitability and philanthropy (Margolis and Walsh 2003), in fact, most large public companies have corporate foundations to "smooth giving" and ensure philanthropic support during periods of low income (Committee Encouraging Corporate Philanthropy 2008). Thus, without comprehensive data on corporate foundation assets and spending, we also do not believe that profitability is an apt measure.

${ }^{8} \mathrm{We}$ also calculated a number of other network measures for each CBSA-level network, including density, centralization, mean clustering coefficient, and the external-internal index, but we found that our simple "mean degree" measure was both parsimonious and highly correlated with the other network measures.

\section{References}

Abzug, R. 2007. Wishful thinking about nonprofits. Society 44(3) 45-47.

Abzug, R., J. S. Simonoff. 2004. Nonprofit Trusteeship in Different Contexts. Ashgate, Hants, UK.

Audia, P. G., J. H. Freeman, P. D. Reynolds. 2006. Organizational foundings in community context: Instruments manufacturers and their interrelationship with other organizations. Admin. Sci. Quart. 51(3) 381-419.

Avi-Yonah, R. S. 2005. The cyclical transformations of the corporate form: A historical perspective on corporate social responsibility. Delaware J. Corporate Law 30(3) 767-818.

Barman, E. 2007. An institutional approach to donor control: From dyadic ties to a field-level analysis. Amer. J. Sociol. 112(5) 1416-1457.

Berle, A. A., Jr. 1931. Corporate powers as powers in trust. Harvard Law Rev. 44(7) 1049-1074.

Bielefeld, W., J. J. Corbin. 1996. The institutionalization of nonprofit human service delivery: The role of political culture. Admin. Soc. 28(3) 362-389.

Boris, E. T., C. E. Steuerle. 2006. Scope and dimensions of the nonprofit sector. W. W. Powell, R. Steinberg, eds. The Nonprofit Sector: A Research Handbook, 2nd ed. Yale University, Press, New Haven, CT, 66-88.

Burris, V. 1987. The political partisanship of American business: A study of corporate political action committees. Amer. Sociol. Rev. 52(6) 732-744.

Committee Encouraging Corporate Philanthropy. 2008. Giving in Numbers: 2008 Edition. CECP, New York. 
Corbin, J. J. 1999. A study of factors influencing the growth of nonprofits in social services. Nonprofit Voluntary Sector Quart. 28(3) 296-314.

Davis, G. F. 2010. Do theories of organizations progress? Organ. Res. Methods 13(4) 690-709.

Davis, G. F., H. R. Greve. 1997. Corporate elite networks and governance changes in the 1980s. Amer. J. Sociol. 103(1) 1-37.

Davis, G. F., K. A. Diekmann, C. H. Tinsley. 1994. The decline and fall of the conglomerate firm in the 1980s: The deinstitutionalization of an organizational form. Amer. Sociol. Rev. 59(4) 547-570.

Dodd, E. M., Jr. 1932. For whom are corporate managers trustees? Harvard Law Rev. 45(7) 1145-1163.

DiMaggio, P. 1986. Nonprofit Enterprise in the Arts: Studies in Mission and Constraint. Oxford University Press, New York.

DiMaggio, P. J. 1991. Constructing an organizational field as a professional project: U.S. art museums, 1920-1940. W. W. Powell, P. J. DiMaggio, eds. The New Institutionalism in Organizational Analysis. University of Chicago Press, Chicago, 267-292.

DiMaggio, P. J., H. K. Anheier. 1990. The sociology of nonprofit organizations and sectors. Annual Rev. Sociol. 16 137-159.

DiMaggio, P. J., W. W. Powell. 1983. The iron cage revisited: Institutional isomorphism and collective rationality in organizational fields. Amer. Sociol. Rev. 48 147-160.

Domhoff, G. W. 1967. Who Rules America? Prentice Hall, Englewood Cliffs, NJ.

Elazar, D. J. 1984. American Federalism: A View from the States, 3rd ed. Harper \& Row, New York.

Elkington, J. 1998. Cannibals with Forks: The Triple Bottom Line of 21st Century Business. New Society Publishers, Stony Creek, CT.

Florida, R. L. 2002. The Rise of the Creative Class: And How It's Transforming Work, Leisure, Community, and Everyday Life. Basic Books, New York.

Freeman, J. H., P. G. Audia. 2006. Community ecology and the sociology of organizations. Annual Rev. Sociol. 32 145-169.

Frumkin, P. 2002. On Being Nonprofit: A Conceptual and Policy Primer. Harvard University Press, Cambridge, MA.

Galaskiewicz, J. 1985. Social Organization of an Urban Grants Economy: A Study of Business Philanthropy and Nonprofit Organizations. Academic Press, Orlando, FL.

Galaskiewicz, J. 1991. Making corporate actors accountable: Institution-building in Minneapolis-St. Paul. W. W. Powell, P. J. DiMaggio, eds. The New Institutionalism in Organizational Analysis. University of Chicago Press, Chicago, 293-310.

Galaskiewicz, J. 1997. An urban grants economy revisited: Corporate charitable contributions in the Twin Cities, 1979-81, 1987-89. Admin. Sci. Quart. 42(3) 445-471.

Galaskiewicz, J., W. Bielefeld, M. Dowell. 2006. Networks and organizational growth: A study of community based nonprofits. Admin. Sci. Quart. 51(3) 337-380.

Glynn, M. A. 2008. Configuring the field of play: How hosting the olympic games impacts civic community. J. Management Stud. 45(6) 1117-1146.

Greenwood, R., A. M. Díaz, S. X. Li, J. C. Lorente. 2010. The multiplicity of institutional logics and the heterogeneity of organizational responses. Organ. Sci. 21(2) 521-539.

Guthrie, D. 2003. Codebook for Corporate-Community Relations Study: 2001-2002 survey of Corporate Involvement. Social Science Research Council, New York.
Hall, P. D. 1987. An overview of the nonprofit sector: A historical overview of the private nonprofit sector. W. W. Powell, ed. The Nonprofit Sector: A Research Handbook. Yale University Press, New Haven, CT, 3-26.

Hall, P. D. 1992. Cultures of trusteeship. P. D. Hall, ed. Inventing the Nonprofit Sector and Other Essays on Philanthropy, Voluntarism, and Nonprofit Organizations. Johns Hopkins University Press, Baltimore, 135-206.

Heilbrun, J., C. M. Gray. 2001. The Economics of Art and Culture, 2nd ed. Cambridge University Press, Cambridge, UK.

Hinings, C. R., R. Greenwood. 2002. Disconnects and consequences in organization theory. Admin. Sci. Quart. 47(3) 411-421.

Hirsch, P. M. 1987. Pack Your Own Parachute: How to Survive Mergers, Takeovers, and Other Corporate Disasters. Addison-Wesley, Reading, MA.

Hoffman, A. 1999. Institutional evolution and change: Environmentalism and the U.S. chemical industry. Acad. Management Rev. 42(4) 351-371.

Hunter, F. 1953. Community Power Structure: A Study of DecisionMakers. University of North Carolina Press, Chapel Hill.

Jensen, M. C. 2002. Value maximization, stakeholder theory, and the corporate objective function. Bus. Ethics Quart. 12(2) 235-256.

Kaysen, C. 1957. The social significance of the modern corporation. Amer. Econom. Rev. 47(2) 311-319.

Kessler, R. C., D. F. Greenberg. 1981. Linear Panel Analysis: Models of Quantitative Change. Academic Press, New York.

Kono, C., D. Palmer, R. Friedland, M. Zafonte. 1998. Lost in space: The geography of corporate interlocking directorates. Amer. J. Sociol. 103(4) 863-911.

Laumann, E. O., J. Galaskiewicz, P. V. Marsden. 1978. Community structure as interorganizational linkages. Annual Rev. Sociol. 4 $455-484$.

Litwak, E., L. F. Hylton. 1962. Interorganizational analysis: A hypothesis on co-ordinating agencies. Admin. Sci. Quart. 6(4) 395-420.

Lounsbury, M. 2007. A tale of two cities: Competing logics and practice variation in the professionalizing of mutual funds. Acad. Management J. 50(2) 289-307.

Margolis, J. D., J. P. Walsh. 2003. Misery loves companies: Rethinking social initiatives by business. Admin. Sci. Quart. 48(2) 268-305.

Marquis, C. 2003. The pressure of the past: Network imprinting in intercorporate communities. Admin. Sci. Quart. 48(4) 655-689.

Marquis, C., J. Battilana. 2009. Acting globally but thinking locally? The enduring influence of local communities on organizations. Res. Organ. Behav. 29 283-302.

Marquis, C., M. Lounsbury. 2007. Vive la resistance: Consolidation and community-level professional counter-mobilization in U.S. banking. Acad. Management J. 50(4) 799-820.

Marquis, C., M. A. Glynn, G. F. Davis. 2007. Community isomorphism and corporate social action. Acad. Management Rev. 32(3) 925-945.

Marquis, C., M. Lounsbury, R. Greenwood, eds. 2011. Communities and Organizations. Research in the Sociology of Organizations, Vol. 33. Emerald Group Publishing, Bingley, UK.

McCarthy, J. D., M. N. Zald. 1977. Resource mobilization and social movements: A partial theory. Amer. J. Sociol. 82(6) 1212-1241.

McElroy, K. M., J. J. Siegfried. 1986. The community influence on corporate contributions. Public Finance Rev. 14(4) 394-414. 
Meyer, J. W., J. Boli, G. M. Thomas, F. O. Ramirez. 1997. World society and the nation-state. Amer. J. Sociol. 103(1) 144-181.

Michels, R. 1962. Political Parties: A Sociological Study of the Oligarchical Tendencies of Modern Democracy. Collier Books, New York.

Mills, C. W. 1956. The Power Elite. Oxford University Press, New York.

Mizruchi, M. S. 1989. Similarity of political behavior among large american corporations. Amer. J. Sociol. 95(2) 401-424.

Mizruchi, M. S. 1996. What do interlocks do? An analysis, critique, and assessment of research on interlocking directorates. Annual Rev. Sociol. 22 271-298.

Nader, L. 1991. Review: Charity begins at home: Generosity and selfinterest among the philanthropic elite. Amer. Anthropol. 93(2) 483-484.

Nocera, J. 2007. Emerald City of giving does exist. New York Times (December 22) http://www.nytimes.com/2007/12/22/business/ 22nocera.html.

Odendahl, T. J. 1990. Charity Begins at Home: Generosity and SelfInterest Among the Philanthropic Elite. Basic Books, New York.

Ostrander, S. A. 1984. Women of the Upper Class. Temple University Press, Philadelphia.

Ostrower, F. 1995. Why the Wealthy Give: The Culture of Elite Philanthropy. Princeton University Press, Princeton, NJ.

Ostrower, F. 2002. Trustees of Culture: Power, Wealth, and Status on Elite Arts Boards. University of Chicago Press, Chicago.

Plaut, V. C., H. R. Markus, M. E. Lachman. 2002. Place matters: Consensual features and regional variation in American wellbeing and self. J. Personality Soc. Psych. 83(1) 160-184.

Powell, W. W., R. Steinberg. 2006. The Nonprofit Sector: A Research Handbook, 2nd ed. Yale University Press, New Haven, CT.

Powell, W. W., D. White, R., K. W. Koput, J. Owen-Smith. 2005. Network dynamics and field evolution: The growth of interorganizational collaboration in the life sciences. Amer. J. Sociol. 110(4) 1132-1206.

Putnam, R. D. 1993. Making Democracy Work: Civic Traditions in Modern Italy. Princeton University Press, Princeton, NJ.

Putnam, R. D. 2000. Bowling Alone: The Collapse and Revival of the American Community. Simon \& Schuster, New York.

Robertson, R., H. H. Khondker. 1998. Discourses of globalization: Preliminary considerations. Internat. Sociol. 13(1) 25-40.

Salamon, L. M. 1987. Partners in public service: The scope and theory of government-nonprofit relations. W. W. Powell, ed. The Nonprofit Sector: A Research Handbook. Yale University Press, New Haven, CT, 99-117.

Salamon, L. M., S. W. Sokolowski. 2005. Nonprofit organizations: New insights from QCEW data. Monthly Labor Rev. 128(9) 19-26.

Saxenian, A. L. 1994. Regional Advantage: Culture and Competition in Silicon Valley and Route 128. Harvard University Press, Cambridge, MA.

Scott, W. R. 2001. Institutions and Organizations, 2nd ed. Sage, Thousand Oaks, CA.

Scott, W. R., M. Ruef, P. J. Mendel, C. A. Caronna. 2000. Institutional Change and Healthcare Organizations: From Professional Dominance to Managed Care. University of Chicago Press, Chicago.

Smith, S. R., M. Lipsky. 1993. Nonprofits for Hire: The Welfare State in the Age of Contracting. Harvard University Press, Cambridge, MA.
Sorenson, O., P. G. Audia. 2000. The social structure of entrepreneurial activity: Geographic concentration of footwear production in the United States, 1940-1989. Amer. J. Sociol. 106(2) 424-462.

Sorge, A. 2005. The Global and the Local: Understanding the Dialectics of Business Systems. Oxford University Press, Oxford, UK.

Stern, R. N., S. R. Barley. 1996. Organizations and social systems: Organization theory's neglected mandate. Admin. Sci. Quart. 41(1) 146-162.

Talcott, S. 2005. Gillette merger opens wounds, possibilities. Boston Globe (January 30) http://www.boston.com/business/articles/ 2005/01/30/gillette_merger_opens_wounds_possibilities/.

U.S. Bureau of the Census. 1906. Census of Manufactures: 1905. Edited by W. M. Steuart. Government Printing Office, Washington, DC.

U.S. Census Bureau. 2007. Metropolitan and micropolitan statistical areas. Retrieved November 23, 2007, http://www.census .gov/population/metro/.

Useem, M. 1988. Market and institutional factors in corporate contributions. Calif. Management Rev. 30(2) 77-88.

Vogus, T., G. F. Davis. 2005. Elite mobilizations for antitakeover legislation, 1982-1990. G. F. Davis, D. McAdam, W. R. Scott, M. Zald, eds. Social Movements and Organizational Theory. Cambridge University Press, Cambridge, UK, 208-257.

Warren, R. L. 1967. The interorganizational field as a focus for investigation. Admin. Sci. Quart. 12(3) 396-419.

Weber, M. 1964. The Theory of Social and Economic Organization, 1st paperback ed. Free Press, New York.

Weisbrod, B. A. 1998. The nonprofit mission and its financing: Growing links between nonprofits and the rest of the economy. B. A. Weisbrod, ed. To Profit or Not to Profit: The Commercial Transformation of the Nonprofit Sector. Cambridge University Press, Cambridge, UK, 1-22.

Christopher Marquis is an associate professor in the Organizational Behavior unit at the Harvard Business School. His research is focused on how firm behavior is shaped by embeddedness in geographic communities and how environmental conditions during founding periods leave a lasting imprint on organizations. He is currently exploring these issues in the context of the global corporate social responsibility and environmental sustainability in China. He received his Ph.D. in sociology from the University of Michigan.

Gerald F. Davis is the Wilbur K. Pierpont Collegiate Professor of Management at the Ross School of Business and a professor of sociology at the University of Michigan. He received his Ph.D. from Stanford University. His research is broadly concerned with the effects of finance on society.

Mary Ann Glynn is the Joseph F. Cotter Professor of Organization Studies and member of the faculties of Management and Organization at the Carroll School of Management, and by courtesy, Sociology, at Boston College. Her research interests are at the intersection of microlevel cognitive processes (e.g., learning, creativity, and intelligence) and macrolevel cultural influences (social norms, institutional arrangements, and status affiliations) on identity, symbolism, and organizational leadership. 